\title{
STIELTJES LIKE FUNCTIONS AND INVERSE PROBLEMS FOR SYSTEMS WITH SCHRÖDINGER OPERATOR
}

\author{
SERGEY BELYI AND EDUARD TSEKANOVSKII
}

\begin{abstract}
A class of scalar Stieltjes like functions is realized as linear-fractional transformations of transfer functions of conservative systems based on a Schrödinger operator $T_{h}$ in $L_{2}[a,+\infty)$ with a non-selfadjoint boundary condition. In particular it is shown that any Stieltjes function of this class can be realized in the unique way so that the main operator $\mathbb{A}$ of a system is an accretive (*) -extension of a Schrödinger operator $T_{h}$. We derive formulas that restore the system uniquely and allow to find the exact value of a non-real parameter $h$ in the definition of $T_{h}$ as well as a real parameter $\mu$ that appears in the construction of the elements of the realizing system. An elaborate investigation of these formulas shows the dynamics of the restored parameters $h$ and $\mu$ in terms of the changing free term $\gamma$ from the integral representation of the realizable function. It turns out that the parametric equations for the restored parameter $h$ represent different circles whose centers and radii are determined by the realizable function. Similarly, the behavior of the restored parameter $\mu$ are described by hyperbolas.
\end{abstract}

Mathematics subject classification (2000): 47A10, 47B44, 46E20, 46F05.

istic) function.

Key words and phrases: Operator colligation, conservative and impedance system, transfer (character-

\section{REFERENCES}

[1] N. I. AKHIEZER AND I. M. GLAZMAN, Theory of linear operators, Pitman Advanced Publishing Program, 1981.

[2] D. Alpay, I. Gohberg, M. A. KaAshoek, A. L. Sakhnovich, Direct and inverse scattering problem for canonical systems with a strictly pseudoexponential potential, Math. Nachr. 215 (2000), 5-31.

[3] D. AlPAY AND E. R. TSEKANOVSKIĬ, Interpolation theory in sectorial Stieltjes classes and explicit system solutions, Lin. Alg. Appl., 314 (2000), 91-136.

[4] YU. M. ARLINSKIĬ, On regular (*)-extensions and characteristic matrix valued functions of ordinary differential operators, Boundary value problems for differential operators, Kiev, 3-13, 1980.

[5] YU. ARLINSKII AND E. TSEKANOVSKIII. Regular (*)-extension of unbounded operators, characteristic operator-functions and realization problems of transfer functions of linear systems. Preprint, VINITI, Dep.-2867, 72p., 1979.

[6] YU. M. ARLINSKIĬ AND E. R. TsEKANOvSKIĬ, Linear systems with Schrödinger operators and their transfer functions, Oper. Theory Adv. Appl., 149, 2004, 47-77.

[7] D. AROv, H. DYM, Strongly regular J -inner matrix-valued functions and inverse problems for canonical systems, Oper. Theory Adv. Appl., 160, Birkhauser, Basel, (2005), 101-160.

[8] D. Arov, H. DyM, Direct and inverse problems for differential systems connected with Dirac systems and related factorization problems, Indiana Univ. Math. J. 54 (2005), no. 6, 1769-1815.

[9] J. A. BALl AND O. J. STAFFAnS, Conservative state-space realizations of dissipative system behaviors, Integr. Equ. Oper. Theory (Online), Birkhäuser, 2005, DOI 10.1007/s00020-003-1356-3.

[10] H. BART, I. GOHBERG, AND M. A. KAASHOEK, Minimal Factorizations of Matrix and Operator Functions, Operator Theory: Advances and Applications, Vol. 1, Birkhäuser, Basel, 1979.

[11] S. V. BELYI AND E. R. TSEKANOVSKIĬ, Realization theorems for operator-valued $R$-functions, Oper. Theory Adv. Appl., 98 (1997), 55-91. 
[12] S. V. Belyi And E. R. TseKANovskiĬ, On classes of realizable operator-valued $R$-functions, Oper. Theory Adv. Appl., 115 (2000), 85-112.

[13] M. S. BRODSKIĬ, Triangular and Jordan representations of linear operators, Moscow, Nauka, 1969 (Russian).

[14] V. A. DeRKACh, E. R. TSEKANOvSKIĬ, On characteristic operator-functions of accretive operator colligations, Ukrainian Math. Dokl., vol. A, no. 8, (1981), 16-20 (Ukrainian).

[15] I. DOVZHENKO AND E. R. TSEKANOVSKIĬ, Classes of Stieltjes operator-functions and their conservative realizations, Dokl. Akad. Nauk SSSR, 311 no. 1 (1990), 18-22.

[16] F. GESZTESY AND E. R. TSEKANOvSKIĬ, On matrix-valued Herglotz functions, Math. Nachr., 218 (2000), 61-138.

[17] F. Gesztesy, N. J. Kalton, K. A. Makarov, E. TseKanovskiĬ, Some Applications of Operator-Valued Herglotz Functions, Operator Theory: Advances and Applications, 123, Birkhäuser, Basel, (2001), 271-321.

[18] S. KHRUSHCHEV, Spectral Singularities of dissipative Schrödinger operator with rapidly decreasing potential, Indiana Univ. Math. J., 33 no. 4, (1984), 613-638.

[19] I. S. KAC AND M. G. KREIN, $R$-functions-analytic functions mapping the upper halfplane into itself, Amer. Math. Soc. Transl. (2) 103, 1-18 (1974).

[20] T. KaTo, Perturbation Theory for Linear Operators, Springer-Verlag, 1966 ath. Dokl. 19, no. 5, 1131-1134 (1978).

[21] B. M. LEVITAN, Inverse Sturm-Liouville Problems, Moscow, Nauka, 1984 (Russian). [English translation: VNU Science Press, Utrecht, 1987]

[22] M. S. LIVŠIC, Operators, oscillations, waves, Moscow, Nauka, 1966 (Russian).

[23] M. A. Naimarkn, Linear Differential Operators II, F. Ungar Publ., New York, 1968.

[24] O. J. STAFFans, Passive and conservative continuous time impedance and scattering systems, Part I: Well posed systems, Math. Control Signals Systems, 15, (2002), 291-315.

[25] E. R. TsEKANOvSKIĬ, Accretive extensions and problems on Stieltjes operator-valued functions realizations, Oper. Theory Adv. Appl., 59 (1992), 328-347.

[26] E. R. TSEKANOVSKIĬ. Characteristic function and sectorial boundary value problems, Investigation on geometry and math. analysis, Novosibirsk, 7, (1987), 180-194.

[27] E. R. TSEKANOVSKII AND YU. L. SHMUL'YAN, The theory of bi-extensions of operators on rigged Hilbert spaces. Unbounded operator colligations and characteristic functions, Russ. Math. Surv., 32 (1977), $73-131$.

[28] V. A. YURKO, Inverse problems for differential operators, Saratv State University Publ., Saratov, 1989 (in Russian). 